\title{
Embriões F1 (Hol X Gir) produzidos in vitro utilizados a fresco em rebanhos leiteiros comerciais e controlado
}

\section{F1 Holstein (Friesan x Gir) embryos produced in vitro used fresh in commercial dairy herds and controlled herds}

Isis Lustosa Goulart, ${ }^{*}$ Ademir de Moraes Ferreira, ${ }^{* *}$ Alessandra de Almeida Ramos, ${ }^{* \star *}$ João Henrique Moreira Viana, ${ }^{* \star *}$ Wanderlei Ferreira de Sá, ${ }^{\star \star * *}$ Luiz Sérgio Camargo, ${ }^{\star \star *}$ Luiz Altamiro Garcia Nogueira*

\begin{abstract}
Resumo
A importância do (F1) para o Brasil é notória, associando rusticidade e produtividade, porém é grande a dificuldade do produtor em manter seu rebanho nesse grau de sangue. No laboratório da Embrapa Gado de Leite em Juiz de Fora, MG foram produzidos in vitro 266 embriões (F1), a partir de complexos cumulus-oócitos (CCO's) de vacas Gir puncionadas e fecundadas com sêmen de touro Holandês. Destes, 53 embriões foram transferidos a fresco para receptoras de rebanhos comerciais de uma Cooperativa da Zona da Mata, MG, enquanto 72 embriões foram inovulados em rebanho controlado da Embrapa Campo Experimental de Coronel Pacheco. A produção de embriões F1 por fecundação in vitro apresentou taxa de produção de blastocisto de $15,58 \%$. A taxa de gestação obtida foi de $26,4 \%$ no rebanho comercial e $40,2 \%$ no rebanho da Embrapa. Considerando-se o nascimento de $50 \%$ de machos e fêmeas, conclui-se que em rebanhos de 100 vacas seriam obtidas 13 fêmeas (13\% de reposição) nos rebanhos comerciais e 20 fêmeas (20\% de reposição) no rebanho da Embrapa. Foram muitas as dificuldades de operacionalização para o uso de dessa biotecnologia que requer um mínimo de escrituração zootécnica, controle sanitário, observação de cios e manejo reprodutivo.
\end{abstract}

Palavras-chave: F1 Holandês x Gir. fecundação in vitro, heterose, PGF2 $\alpha$.

\begin{abstract}
The importance of (F1) to Brazil is notable, associating productivity and rusticity, it is difficult to the producer maintaining the herd in this blood degree. In Embrapa's Gado de Leite, laboratory in the city of Juiz de Fora, M.G., 266 embryos (F1) were produced in vitro from the oocytes of Gir cows, punched and fecundated with Holstein Friesan bull semen. Out of these, 53 embryos were transferred at natural into recipient cows in the commercial herds indicated by the technicians of a great cooperative of Zona da Mata's area, 72 embryos were transferred into recipients of Embrapa's herds under nutritional and sanitary controls. The remainder 139 embryos were frozen due to the lack of adequate recipient cows. The production of $F 1$ embryos through in vitro fecundation of oocytes from Gir cows with semen from Holstein Friesan bull blastocist production rate of $15,58 \%$. The pregnance rate obtained was $26.4 \%$ in the cows from the commercial herds and $40.2 \%$ in the herds of Embrapa Gado de Leite. Considering the birth of $50 \%$ female cows, we can estimate a replacement annual rate of $13 \%$ (26.2\% for gestation) for commercial herds and $20 \%$ (40\% for pregnancy) for the controlled herd. There were many difficulties encountered in the operation, such as (i) the low level of adoption of technology; (ii) little investment in feeding, handling and sanity conditions of the herds; (iii) conditions capable to compromising the utilization of embryos, which requires a minimum of structure in terms of zoo-technical documentation, observation of rutting and reproduction management.
\end{abstract}

Keywords: F1 Holstein x Gir, In vitro fertilization, heterosis, PGF2 $\alpha$.

\section{Introdução}

Os cruzamentos em bovinos são realizados com a finalidade de explorar a heterose (Teodoro, 1996; Madalena, 2001; Madalena, 2004). O F1 tem mostrado melhor desempenho em relação ao $3 / 4,5 / 8,7 / 8 \mathrm{HZ}$ e HPB com relação aos seguintes parâmetros: idade ao 10 parto intervalo de partos, cargas de infestações por bernes, carrapatos e endoparasitas intestinais, taxa de descarte, vida útil e custo de produção (Teodoro et al., 1984; Lemos et al., 1992; Teodoro, 1996; Madalena, 2004). Contudo, um grande problema para a quase totalidade dos produtores de leite com gado mestiço é não ter como manter os rebanhos no grau de sangue desejado, quer seja pela inseminação artificial ou pela monta

* Programa de Pós-Graduação em Medicina Veterinária (Doutorado) - Clínica e Reprodução Animal - Faculdade de Veterinária - Universidade Federal Fluminense - Rua Vital Brazil Filho, 64, CEP 24230-340, Niterói, RJ - Brasil. A quem enviar a correspondência: E-mail: isislustosa@yahoo.com.br

** EMBRAPA - Gado de Leite - Rua Eugênio do Nascimento, 610 - Dom Bosco - Juiz de Fora, MG.

*** SBDA, Centro de Criação de Animais de Laboratório da Fundação Oswaldo Cruz.

**** EMBRAPA - Gado de leite - Juiz de Fora - MG. 
natural. Uma maneira do produtor ver atendido seus anseios de poder manter seu rebanho estável no grau de sangue desejado, é por meio da PIVE (produção in vitro de embriões).

A produção in vitro de embriões e a exploração da heterose são dois métodos de aumentar a produtividade e acelerar o progresso genético em muitos sistemas de produção leiteira, no entanto, não se sabe a influência da heterose nos bovinos produzidos in vitro (Fisher et al., 2000). No Brasil, a produção de embriões in vitro, oriundos de oócitos colhidos de doadoras vivas por meio de aspiração folicular guiada por ultrassonografia (Ovum Pick-up, OPU), tem crescido nos últimos anos. O fato da fêmea Bos taurus indicus produzir dezenas de oócitos em um único procedimento de aspiração folicular, numa relação direta com o número de folículos (Pontes et al., 2009) elevou o Brasil à liderança mundial na produção in vitro de embriões.

Os programas de cruzamento têm despertado a atenção para aplicação nos sistemas de produção leiteira, com a transferência de embriões PIV resultantes de F1 para fêmeas $F 1$, como estratégia para eliminar a perda da heterose e aumentar a variação fenotípica, decorrente de fêmeas F1 acasaladas com touros puros ou cruzados (Hansen, 2006).

São escassas as informações existentes na literatura sobre a eficiência do protocolo de produção in vitro de embriões (PIVE) de F1 (Viana, 2005; Castilho, 2007), biotecnologia que apresenta diversas limitações, como 35 a $40 \%$ de taxa de gestação de embriões inovulados, falta de receptoras em número e qualidade suficientes e a ineficiência atual da criopreservação dos embriões produzidos in vitro, além de maior incidência de abortos nos primeiros meses de gestação (Bertolini e Anderson, 2002; Viana, 2005; Rufino et al., 2006; Castilho, 2007).

Neste estudo, pretendeu-se verificar a possibilidade de reposição de novilhas F1 PIV, utilizando-se Complexos cumullus-oócitos (CCO's) de vacas Gir e sêmen da raça holandesa, obtendo-se as taxas de gestação em rebanhos comerciais (representativos do setor leiteiro), bem como em outro rebanho devidamente controlado, com os quais se pretendeu estimar as possíveis taxas de reposição anual nos referidos rebanhos.

\section{Material e métodos}

\section{Local}

Os embriões foram produzidos no Laboratório de Reprodução Animal da Embrapa Gado de Leite, Juiz de Fora, MG, de março a junho de 2006 (estação das chuvas). Para a transferência dos embriões foram utilizadas receptoras de rebanhos comerciais de uma Cooperativa de grande porte da região da Zona da Mata, MG e vacas do rebanho da Embrapa (Coronel Pacheco, MG).

\section{Doadoras}

Como doadoras dos CCO's, foram usadas 14 vacas nãolactantes da raça Gir (Bos indicus), pluríparas com condição corporal variando de 3,5 a 4,5 (1= muito magra e 5=gorda), de acordo com Ferreira et al. (1999), as vacas foram previamente selecionadas do rebanho controlado da
Embrapa Gado de Leite no Campo Experimental de Coronel Pacheco, MG.

No inverno as doadoras foram suplementadas com silagem de milho, para manutenção da condição corporal durante o período experimental. Os critérios para a seleção incluíram o histórico reprodutivo normal, ciclos estrais regulares e ausência de anormalidades clínicas ou reprodutivas. Todos os animais foram previamente submetidos a exames clínico e ginecológico, sendo usados aqueles sem qualquer alteração clínica ou reprodutiva.

Punções foliculares e recuperação de CCO's - As punções foram realizadas por um mesmo técnico, utilizando-se aparelho de ultrassonografia (Scanner 100S, Pie Medical) e guia de biópsia com transdutor setorial intravaginal de 7,5 Mhz. Folículos com diâmetro superior a $3 \mathrm{~mm}$ foram identificados, e puncionados utilizando-se agulhas 19G e pressão de vácuo de $80 \mathrm{mmHg}$, o que correspondeu a fluxo de $14 \mathrm{~mL} / \mathrm{ml}$ de água. O fluido folicular foi inicialmente recuperado em tubos plásticos de $50 \mathrm{~mL}$ (tipo Falcon) contendo $15 \mathrm{~mL}$ de meio PBS (meio de Dullbeco modificado), aquecido a $37^{\circ} \mathrm{C}, 100 \mathrm{UI} / \mathrm{mL}$ de heparina (Liquemine $\AA$, Roche). Após a punção os CCO's foram separados em filtro de coleta de embriões com malha de $80 \mu$ (Milipore). Os CCO's recuperados foram transferidos para placas de cultivo contendo meio PBS acrescido de $10 \%$ de SFB, a $37^{\circ} \mathrm{C}$ e avaliados em estereomicroscópio com aumento final de 50x, por um mesmo técnico.

Foram selecionados CCO's com no mínimo três camadas de células da granulosa, compactas e citoplasma homogêneo. Os CCO's selecionados foram transferidos para meio Tissue Culture Medium (TCM 199) tamponado com Hepes e transportados para o laboratório da Embrapa Gado de Leite, em Juiz de Fora, MG, distante $40 \mathrm{Km}$ (com tempo médio de transporte de 40 minutos a uma hora), em incubadoras portáteis de temperatura $37^{\circ} \mathrm{C}$, onde foram maturados in vitro.

Maturação e Fecundação dos CCO's selecionados - Os CCO's foram maturados in vitro em $400 \mu$ de meio TCM-199 tamponado com bicarbonato de sódio, acrescido de FSH e $10 \%$ de soro de vaca em estro, por 24 horas, em estufa incubadora a $38,5^{\circ} \mathrm{C}$ com $5 \%$ de $\mathrm{CO} 2$ em ar atmosférico e $95 \%$ de umidade. Após a maturação, todos os CCO's foram fertilizados in vitro com sêmen convencional congelado de um touro da raça Holandesa, de fertilidade conhecida. Os espermatozoides foram selecionados pelo método de swimup. Tal processo envolve a incubação do sêmen em 800 microlitros de meio SPTL por 1 hora em estufa a 5\% de CO2, $95 \%$ de umidade e $38^{\circ} \mathrm{C}$. Após este período o sobrenadante contendo os espermatozóides viáveis foi centrifugado por 8 minutos. O sedimento final foi ressuspendido em 250 microlitros de meio Fert-talp acrescido de 20 microgramas/ $\mathrm{ml}$ de heparina. A fecundação in vitro foi realizada em gotas de $100 \mu \mathrm{L}$ de meio Fert-Talp em placa de Petri, acrescido de $10 \mu \mathrm{g} / \mathrm{mL}$ de heparina, cobertas com óleo mineral, com concentração de 2,0 x 106 espermatozoides $/ \mathrm{mL}$ por um período de aproximado de 20 a 22 horas. Foram utilizados grupos de 10 a 30 oócitos por hora de fecundação/cultivo.

Cultivo in vitro - Os possíveis zigotos foram semidesnudados em meio Talp-Hepes e, em seguida, transferidos para gotas de 50 microlitros de meio CR2aa (Rosenkranks e First, 1994), 
acrescido de $10 \%$ de SFB, onde foram co-cultivados com células da granulosa, sob óleo mineral, nas mesmas condições da fecundação por sete dias. Após 48 horas de cultivo, $50 \%$ do meio foi renovado e a taxa de clivagem foi avaliada 72 horas após a fertilização, quando também foi realizada a troca de $50 \%$ do meio CR2aa. A taxa de produção de blastocistos foi avaliada no sétimo dia.

\section{Receptoras}

Foram utilizadas receptoras (vacas e novilhas) de 15 rebanhos leiteiros comerciais, com produção média de 463,4 L/dia; sendo os proprietários associados a uma Cooperativa de grande porte (recepção diária de $300.000 \mathrm{~L}$ de leite) da região da Zona da Mata, em Minas Gerais. Os rebanhos comerciais foram indicados por técnicos da Cooperativa parceira, do Laboratório da Embrapa, sem interferência do pesquisador.

\section{- Critérios de pré-seleção}

A condição corporal das potenciais receptoras foi avaliada e estas foram previamente submetidas a exames clínicos e ginecológicos (palpação retal e ultrassonografia), sendo selecionadas somente as fêmeas que não apresentaram alterações clínicas ou reprodutivas, que já tinham pelo menos 60 dias de paridas e que apresentavam atividade ovariana luteal cíclica (AOLC). A condição reprodutiva de cada animal foi anotada: anestro, ciclando, gestantes ou portadoras de patologias nos órgãos genitais (cistos, infecções, neoplasias, infecções etc.), bem como as dificuldades encontradas na operacionalização desta técnica nos rebanhos.

- Protocolo de sincronização, coleta e inovulação

As receptoras disponibilizadas passaram por outra seleção onde, apenas as que apresentavam corpo lúteo, receberam uma aplicação de prostaglandina na $2^{\mathrm{a}}$ feira da semana seguinte para sincronização de cios (foram efetivamente sincronizadas). O cio foi observado pelo produtor por três dias, quando então foi comunicado à Embrapa o número de receptoras que apresentavam sinais de estro. Considerouse receptoras aptas a inovulação as que apresentavam corpo lúteo na quinta feira da semana seguinte (Figura 1). Para auxílio na detecção deste corpo lúteo foi utilizado um aparelho de ultrassonografia.

As coletas de CCO's na Embrapa (CECP) ocorreram na $3^{\text {a }}$ feira à tarde e 4⿳亠丷⿵冂⿱⺊口灬 feira pela manhã (1-2 dias após a aplicação de prostaglandinas nas receptoras nas fazendas), e na $5^{\underline{a}}$ feira da próxima semana os embriões $\mathrm{F} 1$ PIVE (6 a 8 dias de idade), a fresco, foram levados às propriedades, onde os pesquisadores, após novo exame inovularam as receptoras aptas (que apresentavam corpo lúteo) (Figura 1).

\section{Destino dos embriões}

Parte dos embriões foi transferida, a fresco, para rebanho da Embrapa (controle) e parte para rebanhos leiteiros comerciais distantes do laboratório de origem, em receptoras previamente selecionadas e sincronizadas.

\section{Avaliação}

Após 55 dias da inovulação foi obtida a taxa de gestação através de palpação retal, sendo feita uma estimativa da possível taxa de reposição anual do rebanho, nas condições do presente experimento.

\section{Análise estatística}

Foi feita análise descritiva dos dados, caracterizando as medidas de posição e dispersão, considerando-se o número de CCO's recuperados, número de CCO's viáveis, número de clivagens e número de blastocistos obtidos. As taxas de gestação das receptoras inovuladas nos rebanhos comerciais e no rebanho da Embrapa foram analisados pelo teste Qui-quadrado.

\section{Resultados}

Como se verifica na Tabela 1, das 587 fêmeas disponibilizadas dos rebanhos comerciais, apenas 209 (35,6\%) foram utilizadas, pois apresentavam atividade ovariana luteal cíclica (AOLC). Das fêmeas não utilizadas, $251(42,7 \%)$ estavam em anestro, com escore corporal entre 2,0 e 3,0, 100 (17\%) encontravam-se gestantes sem que tivessem sido diagnosticadas e $27(4,6 \%)$ apresentavam patologias do trato genital.

Nos rebanhos comerciais, das receptoras selecionadas por apresentarem atividade ovariana luteal cíclica (AOLC), 81,3\% (170/209) foram devidamente sincronizadas com as injeções de cloprostenol (PGF2 $\alpha$ ), das quais apenas 46,5\% (79/170) foram observadas em cio, com $67,1 \%$ (53/79) apresentando corpo lúteo no dia das inovulações (Tabela 2). No rebanho

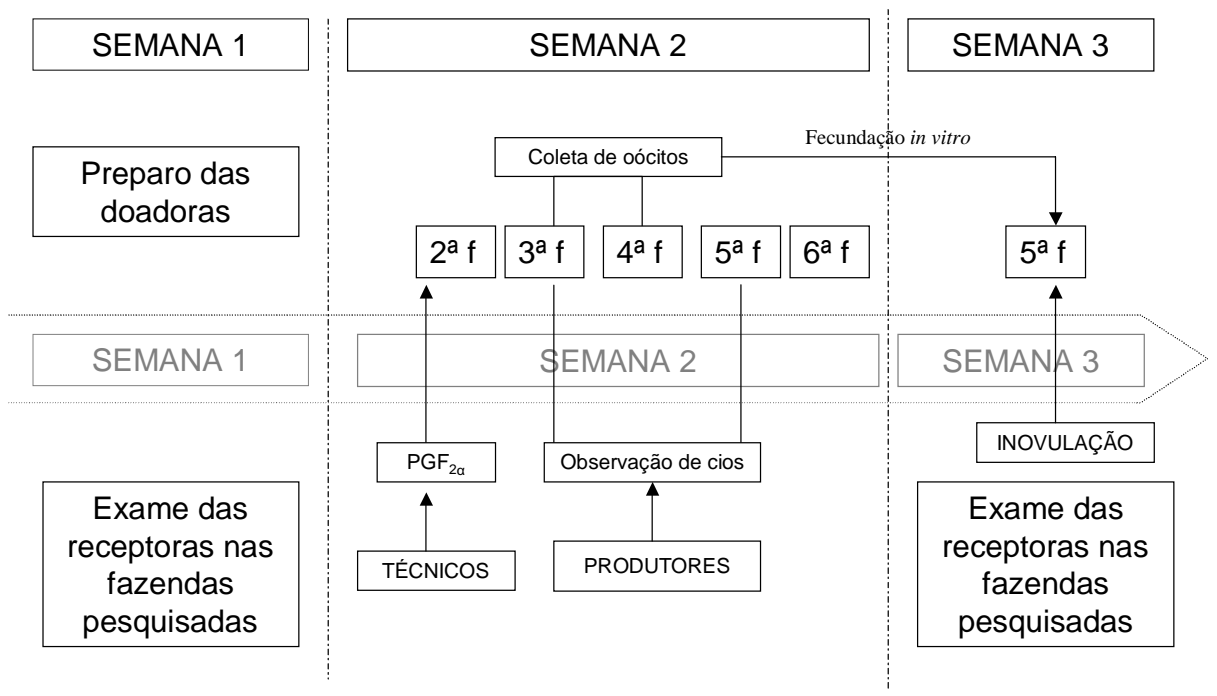

Figura 1: Esquema de sincronizaçao de receptoras e preparo de doadoras 
controlado, 78,7\% (122/155) das receptoras foram sincronizadas por apresentarem corpo lúteo no momento da aplicação da PGF2 $\alpha$ e 80,3\% (98/122) foram observadas em cio, tendo sido inovuladas 75,5\% (74/98) (Tabela 2).

Setenta e duas horas após o semidesnudamento, a taxa de clivagem foi de 44,52\% (760/1707), enquanto a taxa de produção de blastocistos por oócito clivado, avaliada após sete dias, foi de 15,58 (266/1707).

A taxa de prenhez do rebanho controlado foi de 40,2\% (29/ 72) e a dos rebanhos comerciais $26,4 \%$ (14/53), conforme demonstrado na Tabela 3. Estes índices não apresentam diferença estatística significativa $(P>0,05)$.
Algumas dificuldades de operacionalização nos 15 rebanhos comerciais foram observadas, como:

1) Falhas na observação e anotação do cio.

2) Falhas na escrituração zootécnica das propriedades.

3) Falta de compromisso dos produtores, com pouca disponibilidade de mão de obra para realizar o manejo das receptoras.

4) Contenção inadequada das receptoras no momento da inovulação.

5) Atraso na transferência, decorrente do tempo de viagem e atraso no manejo das receptoras.

Tabela 1: Resultados dos exames ginecológicos das receptoras de 15 rebanhos leiteiros comerciais destacando a condição reprodutiva e o escore corporal das mesmas

\begin{tabular}{|c|c|c|c|c|c|c|c|c|}
\hline & \multicolumn{3}{|c|}{ NOVILHAS } & \multicolumn{3}{|c|}{ VACAS } & \multicolumn{2}{|c|}{ TOTAL } \\
\hline & $n$ & $\%$ & Escore & $n$ & $\%$ & & $n$ & $\%$ \\
\hline Anestro & 57 & $35,8 \%$ & 3,0 & 194 & $45,3 \%$ & 2,0 & 251 & $42,7 \%$ \\
\hline Atividade Ovariana Luteal Cíclica (AOLC) & 76 & $47,8 \%$ & 3,5 & 133 & $31,0 \%$ & 2,5 & 209 & $35,6 \%$ \\
\hline Gestantes & 26 & $16,3 \%$ & 3,5 & 74 & $17,3 \%$ & 2,5 & 100 & $17,0 \%$ \\
\hline Patologias & 0 & $0,0 \%$ & - & 27 & $6,3 \%$ & 2,0 & 27 & $4,6 \%$ \\
\hline Cistos foliculares & - & - & & 10 & $37,0 \%$ & & - & - \\
\hline Aderências & - & - & & 8 & $29,6 \%$ & & - & - \\
\hline Infecções uterinas & - & - & & 5 & $18,5 \%$ & & - & - \\
\hline Neoplasias & - & - & & 2 & $7,4 \%$ & & - & - \\
\hline Vaginites & - & - & & 2 & $7,4 \%$ & & - & - \\
\hline Total & 159 & $100 \%$ & & 428 & $100 \%$ & & 587 & $100 \%$ \\
\hline
\end{tabular}

Tabela 2: Comparação das receptoras (vacas e novilhas) selecionadas por AOLC, efetivamente sincronizadas com uma dose de PGF2Ü, observadas em cio e aptas para inovulação nos 15 rebanhos bovinos leiteiros comerciais e no rebanho controlado

\begin{tabular}{lccccccc}
\hline $\begin{array}{l}\text { Rebanho } \\
\text { Comercial }\end{array}$ & $\begin{array}{c}\text { Selecionadas (por } \\
\text { AOLC) }\end{array}$ & $\begin{array}{c}\text { Efetivamente } \\
\text { sincronizadas }\end{array}$ & $\%$ & $\begin{array}{c}\text { Observadas em } \\
\text { cio }\end{array}$ & $\%$ & $\begin{array}{c}\text { Aptas para } \\
\text { inovulação }\end{array}$ & \begin{tabular}{c}
$\%$ \\
\hline Novilhas
\end{tabular} \\
Vacas & 133 & 101 & 75,6 & 53 & $53,1^{\text {a }}$ & 35 & 65,5 \\
\hline Total & 76 & 69 & 91,4 & 26 & $36,8^{\mathrm{c}}$ & 18 & 70,4 \\
\hline \hline Rebanho & $\mathbf{2 0 9}$ & $\mathbf{1 7 0}$ & $\mathbf{8 1 , 3}$ & $\mathbf{7 9}$ & $\mathbf{4 6 , 5}$ & $\mathbf{5 3}$ & $\mathbf{6 7 , 1}$ \\
\hline Controlado & & & & & & & \\
\hline Novilhas & 69 & 50 & 72,5 & 41 & $82,0^{\text {b }}$ & 30 & 73,2 \\
Vacas & 86 & 72 & 83,7 & 57 & $79,2^{\text {d }}$ & 42 & 73,7 \\
\hline Total & $\mathbf{1 5 5}$ & $\mathbf{1 2 2}$ & $\mathbf{7 8 , 7}$ & $\mathbf{9 8}$ & $\mathbf{8 0 , 3}$ & $\mathbf{7 4}$ & $\mathbf{7 5 , 5}$ \\
\hline \hline
\end{tabular}

Valores seguidos por letras minúsculas distintas na mesma coluna diferem entre si $(\mathrm{P}<0,05)$.

Tabela 3: Taxa de embriões transferidos, receptoras gestantes a partir de embriões F1 transferidos a fresco em rebanhos comerciais e controlado

\begin{tabular}{lccc}
\hline \multicolumn{1}{c}{ Rebanho } & Embriões transferidos & Receptoras gestantes & Taxa de gestação (\%) \\
\hline Controle & 72 & 29 & $40,2^{\mathrm{a}}$ \\
Comercial & 53 & 14 & $26,4^{\mathrm{a}}$ \\
\hline Total & $\mathbf{1 2 5}$ & 43 & 33,3 \\
\hline \hline
\end{tabular}

Valores seguidos por letras minúsculas iguais na mesma coluna não diferem entre si $(P>0,05)$. 


\section{Discussão}

O resultado das avaliações realizadas nos rebanhos mostra (tabela 1) uma realidade bem conhecida na pecuária leiteira nacional, com a maioria das vacas mais de 60 dias pósparto ainda em anestro, enquanto algumas estavam gestantes ou com patologias de órgãos genitais sem que fosse do conhecimento do produtor (Gregory et al., 2009). A associação de anestro com a condição corporal também ficou evidente, com estas vacas apresentando uma condição corporal média inferior a 2,5.

Foi alta a taxa de receptoras do rebanho comercial descartadas do programa por não apresentarem condições de serem inovuladas - 64,4\%, sendo 42,76\% em decorrência de anestro nutricional, com a presença de grande número de vacas e novilhas malnutridas e magras, caracterizando um manejo nutricional deficiente, o que representa o principal fator limitante para a maximização da exploração do gado leiteiro (Ferreira, 2000; Borges, 2006; Gregory et al., 2009).

Alguns trabalhos relatam cerca de $65 \%$ a $75 \%$ de eficiência na sincronização de cio com prostaglandina (Fernandes et al., 1994, Fernandes et al., 2002; Bó et al., 2004; Barros et al., 2006). Foi baixa a taxa de observação de cios $(<50 \%)$ no rebanho comercial podendo ter como razão a baixa adoção da técnica de inseminação artificial (IA) nas propriedades trabalhadas, motivo pelo qual os responsáveis não estavam habituados à rotina de observação e anotação de cios, informação vital para o sucesso da transferência de embriões (TE). Para um programa de TE apresentar uma eficiência desejável, cerca de 70 a $80 \%$ dos animais em estro devem ser corretamente identificados (Teodoro, 1996; Martins e Espindola, 2001; Goulart, 2003;

\section{Referências}

BARROS, F.R.O., DIAS, L.O.P., FANTINI, D.A., MIGUEZ, P.H., BERTAN, C.M., BINELLI, M. O etanol estimula a liberação de prostaglandina-F2 alfa, mas não causa luteólise em bovinos. E. Ciências Agrárias. Medicina Veterinária. Reprodução Animal. Anais da 58ª Reunião Anual da SBPC. Florianópolis, 2006.

BERTOLINI, M.; ANDERSON, G.B. The placenta as a contributor to production of large calves. Theriogenology, v. 57, p. 181-187, 2002. BÓ, G.A., MORENO, D., CUTAIA, L., BARUSELLI, P.S., REIS, E.L. Manipulação hormonal do ciclo estral em doadoras e receptoras de embrião bovino. Acta Scientiae Veterinariae, v. 32, supl., p. 1-22, 2004.

BORGES, A. M. Inter-relações entre nutrição e reprodução em fêmeas bovinas de corte. In: V Simpósio de Produção de Gado de Corte e I Simpósio Internacional de Produção de Gado de Corte, 2006. Viçosa. Anais. Viçosa: UFV, p. 555-597, 2006.

CALLESEN, H. Preovulatory evaluation in superovulatory responses in donor cattle. Theriogenology, v. 30, p. 477-488, 1988.

CAMARGO, L.S.A. Identificação do cio. Disponível em: http:// www.cnpgl.embrapa.br/pastprod/textos/folha47.html, acesso em 19/ 05/06.

CASTILHO, C. Influência do diâmetro e da fase folicular sobre a competência in vitro de oócitos obtidos de novilhas da raça Nelore. Arq. Bras. Med. Vet. Zootecnia, v. 59, n. 2, p. 288-294, 2007.

FERNANDES, C.A.C, VIANAJ.H.M., FERREIRAA.M., SÁ,W.F. Fertilidade de novilhas após aborto induzido com cloprostenol, Arq. Bras. Med. Vet. Zootec. v. 54 n. 3 Belo Horizonte, junho 2002.
Camargo, 2006), o que está em concordância com os valores encontrados no rebanho controlado da Embrapa. Observouse diferença significativa $(P<0,05)$ quanto ao número de receptoras observadas em cio, entre os dois rebanhos citados, conforme demonstrado na Tabela 2.

Em termos de produção de embriões F1 PIVE, os resultados foram inferiores aos valores médios citados na literatura, ou seja, em torno de $40 \%$, embora exista uma variação muito grande de resultados (0 a 70\%) (Reis et al., 2006; Paschoal e Gradela, 2007). Já a taxa de prenhez obtida nos rebanhos comerciais $(26,4 \%)$ não foi significativamente menor $(P>0,05)$ que a taxa de prenhez do rebanho controlado (40,2\%), e está em concordância com a literatura, onde são encontrados índices de zero a 60\% (Reis et al., 2006; Paschoal e Gradela, 2007). As taxas de gestação obtidas a partir de embriões produzidos in vitro podem ser bastante variáveis. Esta variação está associada à qualidade do embrião, o que, por sua vez, depende das condições de produção de cada laboratório. Além disso, como na transferência de embriões (TE), o estado reprodutivo e nutricional das receptoras também interfere nos resultados.

\section{Conclusões}

É possível fazer a reposição de matrizes F1 ( $\mathrm{Hol}$ x Gir), utilizando-se embriões F1 PIVE.

Constituem entraves à adoção da PIVE em rebanhos comerciais a deficiência de escrituração zootécnica, a falta de compromisso dos produtores, mão de obra para realizar o manejo das receptoras e para identificação de cio e local para contenção das receptoras no momento da inovulação.

FERNANDES, C.A.C.; TORRES, C.A.A.; COSTA, E.P. Comparação entre doses e vias de aplicação de cloprostenol para sincronização de estro em bovinos. Revista Brasileira de Reprodução Animal, v. 18, n. 3-4, p. 105-109, 1994.

FERREIRA, A.M. Alimentação e comportamento reprodutivo de vacas leiteiras. In: X Simpósio de Goiânia. Anais, Goiânia, p. 1-11, 2000.

FERREIRA, A de M.; TORRES, C. A.A.; SILVA, J.F.C. Peso para recuperação da atividade ovariana luteal cíclica em vacas leiteiras mestiças em anestro. Pesquisa Agropecuária Brasileira, Brasília, DF, v. 34, n. 3, p. 481-485, mar.1999.

FISCHER, A.E, Bernal, D.P., Gutierrrez-Robayo C, Rutledge J.J, Estimates of heterosis for in vitro embryo production using reciprocal crosses in cattle, Theriogenology, v. 54, p. 1433-1442, 2000.

GOULART, I.L. Determinação do melhor momento da inseminação artificial em bovinos. 2003. 40 f. Rio de Janeiro, RJ. Dissertação (Mestrado em Ciências Veterinárias) - Curso de Pós-Graduação em Medicina Veterinária, Universidade Federal Rural do Rio de Janeiro, 2003.

GREGORY, R.M.; RODRIGUES, J.L. Efeitos da prostaglandina na sincronização de cios de doadoras e receptoras de embriões em bovinos. Revista Brasileira de Reprodução Animal, v. 6, n. 3-4, p. 9, 1982.

GREGORY, R.M.; MELO, I.C.; BESKOW, A.; MATTOS, R.C.; JOBIM, M.I.M; GREGORY, J.W. Dinâmica folicular e uso de hormonioterapias na regulação do ciclo estral na vaca. Anais do Congresso Brasileiro de Reprodução Animal, 18., Belo Horizonte, MG, 2009.

HANSEN P.J, Realizing the promise of IVF in cattle: an overview. Theriogenology, v. 65, p. 119-125, 2006. 
JOHNSON, S.K.; AND DAY, M.L. Methods to reduce or eliminate detection of estrus in a melengestrol acetate-PGF2 alfa protocol for synchronization of estrus in beef heifers. Departament of animal sciences and industry, Kansas State University. Journal of Animal. Science, v. 82, p. 3071-3076, 2004.

LEMOS, A.M.; MADALENA, F.E.; TEODORO, R.L.; BARBOSA, R.T.; MONTEIRO,J.B.N. Comparative of six Holstein Friesian x Guzerá grades in Brazil : 5- age at first calving. Revista Brasileira de Genética, v. 15, n. 1, p. 73-83, 1992.

MADALENA, F.E. Por que F1? In: 5 Encontro de Produtores de Gado Leiteiro F1, 2004, Belo Horizonte, MG. Anais do $5^{\circ}$ Encontro de Produtores de Gado Leiteiro F1. Belo Horizonte: FEP MVZ Editora, p. 1-21, 2004.

MADALENA, F.E. A vaca econômica. In: MADALENA, F.E.; TEODORO, R.L. Encontro de produtores de F1: jornada técnica sobre utilização de F1 para produção de leite, 3, 2001, Anais, Juiz de Fora, MG, Embrapa Gado de Leite, 92 p. (p. 9-16), 2001.

MADALENA, F.E. Encontro de Produtores de F1: Apresentação. Caderno Técnico da Escola de Veterinária da UFMG, n. 18, p. 3-4, 1996.

MARTINS, C.E.; ESPINDOLA, H.D. Capacitação em Tecnologia para produção de leite nos trópicos. Caderno técnico, Embrapa Gado de Leite, Juiz de Fora- MG, p. 196, 2001.

PASCHOAL, D.M.; GRADELA, A.; Produção in vitro de embriões bovinos: revisão de literatura; Revista CFMV; Brasília, DF, Ano XII, n. 41, 2007.
PONTES J., Nonato-Júnior I, Sanches B, Ereno-Júnior j, Uvo S, Barreiros T, Oliveira J, Hasler J, Seneda M, Comparison of embryo yield and pregnancy rate between in vivo and in vitro methods in the same Nelore (Bos indicus) donor cows, Theriogenology, v. 71, p. 690-697, 2009.

REIS, A. METELO, R., SANTOS, P., SILVA, F. M. Efeito da estrutura ovárica e da idade de bovinos da raça Holstein Friesian na quantidade e qualidade de ovócitos e de embriões produzidos in vitro. Brazilian Journal Veterinary Animal Science, v. 43, n. 5, p. 629-636, 2006.

ROSENKRANKS, C.F.; FIRST, N.L. Effect of free animo acids and vitamins on cleavage and developmental rate of bovine zygotes in vitro. Journal Animal Science, v. 72, p. 434-437, 1994.

RUFINO, F. A, Seneda, M.M., Alfieri, A.A, Determinação do sexo de embriões bovinos produzidos in vitro: uma revisão de métodos com ênfase para a PCR, Archives of Veterinary Science, v. 11, n. 1, p. 1 7, 2006.

TEODORO, R. L. Pesquisas em Cruzamentos: Resultados Zootécnicos. Caderno Técnico Escola de Veterinária da UFMG, n. 18, p. 11-18, 1996.

TEODORO, R.L.; LEMOS, A.M.; BARBOSA, R. T.; MADALENA, F.E. Comparative performance of six Holstein Friesian x Guzerá grades in Brazil: 2- Traits related to the onset the sexual function. Animal Production, v. 38, n. 2, p. 165-170, 1984.

VIANA, J.H.M.; Por que a fecundação in vitro faz tanto sucesso; DBO Genética, artigo, p. 50-54; set. 2005. 